\title{
Erratum
}

\section{A randomized double-blind crossover trial comparing subthalamic and pallidal deep brain stimulation for dystonia}

\section{Clinical article}

To The Editor: We appreciate the publication of our paper entitled "A randomized double-blind crossover trial comparing subthalamic and pallidal deep brain stimulation for dystonia. Clinical article" (J Neurosurg published online ahead of print on October 11, 2013; DOI: 10.3171/ 2013.8.JNS13844).

After publication of this article online, we realized that the figure we had submitted for Fig. 2 and the cover of the December 2013 issue of the Journal of Neurosurgery was inappropriate because of copyright issues. We thereby decided to replace the figure at this time.

The new figure and legend are given below.

We apologize to the editor and readers. We are pleased to have the opportunity to make this correction. The error was corrected online as of November 22, 2013, and will appear correctly in print.

LisBeth SCHJERLing, M.D. Lena E. Huermind, M.D., Ph.D. Bo JESPERSEN, M.D. Flemming F. Madsen, M.D., D.SC.

JanNick BRenNum, M.D., D.SC. STEEn R. Jensen, R.N. AnNemette LøKkegaArd, M.D., Ph.D. Merete Karlsborg, M.D. Copenhagen University Hospital Copenhagen, Denmark

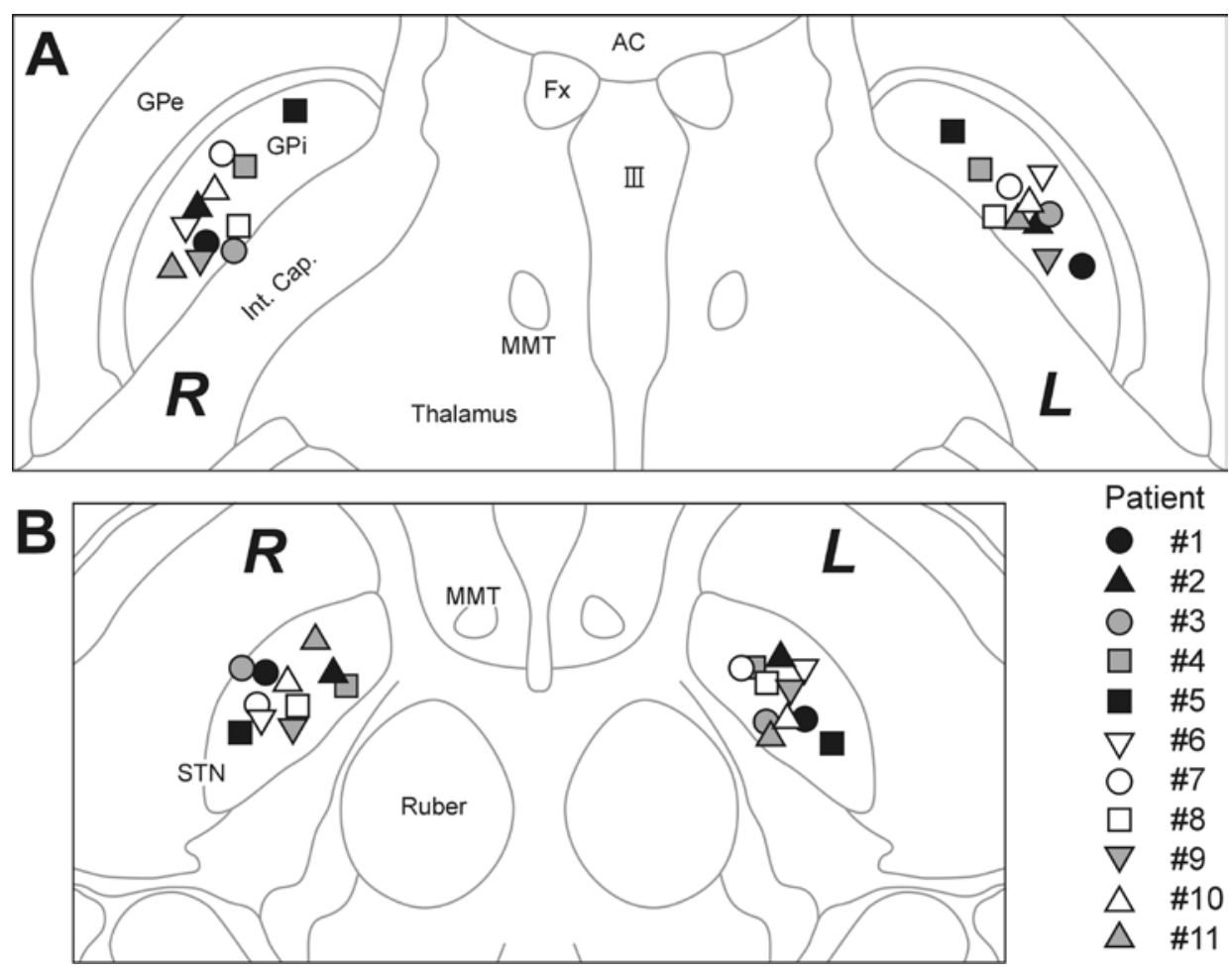

FIG. 2. Eleven patients had postoperative documentation of the electrode placement: 4 by MRI, 3 by CT, and 4 by both. The center of each electrode was marked on axial slides of postoperative CT or FLAIR MR images, which were fused to preoperative T2-weighted MR images to ensure that anatomical structures were not influenced by artifacts. The positions are marked on a standard anatomical atlas. $\mathrm{AC}=$ anterior commissure; $\mathrm{Fx}=$ fornix; $\mathrm{GPe}=$ globus pallidus externus; $\mathrm{GPi}=$ globus pallidus internus; Int. Cap. = internal capsule; MMT = mamillothalamic tract; Ruber = nucleus ruber (red nucleus); STN = subthalamic nucleus; III $=$ third ventricle. A: GPi. B: STN.

Please include this information when citing this paper: published online November 22, 2013; DOI: 10.3171/2013.11.JNS13844a. 